\title{
Activity-Dependent Callosal Axon Projections in Neonatal Mouse Cerebral Cortex
}

\author{
Yoshiaki Tagawa $^{1,2}$ and Tomoo Hirano ${ }^{1}$ \\ ${ }^{1}$ Department of Biophysics, Kyoto University Graduate School of Science, Kitashirakawa-Oiwake-cho, Sakyo-ku, Kyoto 606-8502, Japan \\ ${ }^{2}$ CREST, Japan Science and Technology Agency, Kawaguchi, Saitama 332-0012, Japan
}

Correspondence should be addressed to Yoshiaki Tagawa, tagawa@neurosci.biophys.kyoto-u.ac.jp

Received 31 July 2012; Accepted 21 October 2012

Academic Editor: Matteo Caleo

Copyright ( $\odot 2012$ Y. Tagawa and T. Hirano. This is an open access article distributed under the Creative Commons Attribution License, which permits unrestricted use, distribution, and reproduction in any medium, provided the original work is properly cited.

Callosal axon projections are among the major long-range axonal projections in the mammalian brain. They are formed during the prenatal and early postnatal periods in the mouse, and their development relies on both activity-independent and -dependent mechanisms. In this paper, we review recent findings about the roles of neuronal activity in callosal axon projections. In addition to the well-documented role of sensory-driven neuronal activity, recent studies using in utero electroporation demonstrated an essential role of spontaneous neuronal activity generated in neonatal cortical circuits. Both presynaptic and postsynaptic neuronal activities are critically involved in the axon development. Studies have begun to reveal intracellular signaling pathway which works downstream of neuronal activity. We also review several distinct patterns of neuronal activity observed in the developing cerebral cortex, which might play roles in activity-dependent circuit construction. Such neuronal activity during the neonatal period can be disrupted by genetic factors, such as mutations in ion channels. It has been speculated that abnormal activity caused by such factors may affect activity-dependent circuit construction, leading to some developmental disorders. We discuss a possibility that genetic mutation in ion channels may impair callosal axon projections through an activity-dependent mechanism.

\section{Introduction}

For developmental neuroscientists, interhemispheric axons (callosal axons) have been an excellent model to study how long-range axonal projections develop in the brain. Callosal axons form one of the major axonal tracts in the mammalian brain, the corpus callosum, which visibly connects the two cerebral hemispheres. In the past decades, detailed anatomical and physiological studies in animal models have improved our understanding of the organization and development of callosal connections [1-8]. Recent genetic studies have revealed molecular signals critical for the identity specification of callosal projection neurons [9-12] and axon guidance during the midline crossing [13-27]. These findings have been relevant for not only basic neuroscientists but also clinical neuroscientists, because malformations such as partial or complete agenesis of the corpus callosum are associated with many human congenital disorders $[18,22]$.

In general, during formation of connections in the developing brain, there is an early phase relying on activity independent mechanisms (such as those involving axon guidance molecules) and a later phase requiring neuronal activity [28-33]. As for callosal connections, an important role of neuronal activity in their formation is well established. For example, in the visual cortex, sensory-driven neuronal activity is crucial for the formation of callosal connections [7, 34-37]. In addition, recent studies using mice as a model have begun to reveal critical roles of neuronal activity spontaneously generated in neonatal cortical circuits [38-41]. Sophisticated in vivo $\mathrm{Ca}^{2+}$ imaging and multiunit recordings have uncovered several distinct patterns of neuronal activity occurring in neonatal mouse cortex during the periods when callosal axon projections develop [42-50]. Interestingly, some of the activities occurring in both hemispheres are synchronized [47]. These new findings suggest that callosal axon projections and connection formation are shaped not only by sensory-driven neuronal activity but also by spontaneous neuronal activity generated in the developing cerebral cortex. 


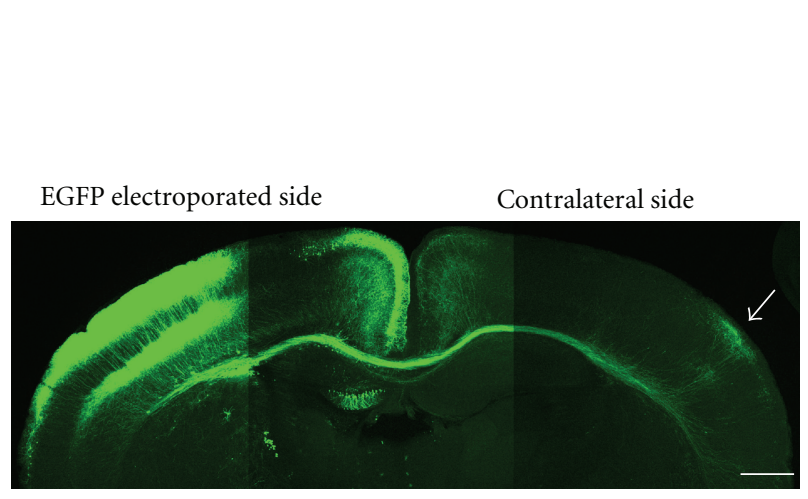

(a)

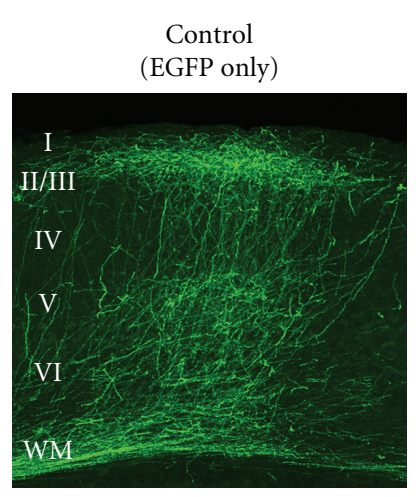

(b)

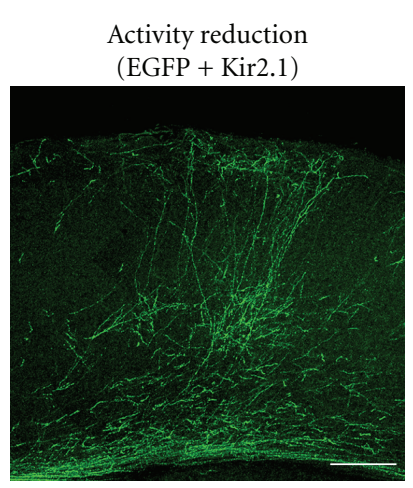

(c)

FIGURE 1: Visualization of callosal axon projections and an effect of activity reduction. (a) An in utero electroporation-mediated gene transfer method [38] was used to unilaterally express EGFP in layer 2/3 cortical neurons (electroporated side). EGFP-labeled callosal axons extend through the corpus callosum, and project densely to a narrowly restricted region in the contralateral cortex (arrow). Scale bar, $500 \mu \mathrm{m}$. (b) EGFP-labeled control callosal axons show lamina specific projection pattern. (c) Reduction of neuronal activity in callosal projection neurons disturbs their axonal projections. Adapted from [38]. Scale bar, $200 \mu \mathrm{m}$.

In this paper, we focus on activity-dependent mechanism of callosal projection formation. First, we review recent findings about the role of spontaneous neuronal activity in callosal axon projections. We then summarize the patterns of neuronal activity observed in the developing cerebral cortex, which might play a role in activity-dependent callosal axon projections and cortical circuit formation in general. Finally, we discuss a possibility that abnormal neuronal activity caused by genetic mutations in ion channels might influence activity-dependent phases of callosal axon projections, leading to some deficit in the structure/function of the corpus callosum.

\section{Activity-Dependent Development of Callosal Axon Projections in the Mouse}

Callosal axons are derived from cortical layer $2 / 3$ and 5 neurons [51]. During development, they extend down towards the white matter, turn medially towards the midline, run in the white matter, cross the midline, extend through the white matter of the contralateral cortex, locate their target neocortical area for innervation, turn and make terminal arbors and synapses in the correct cortical layers (Figure 1). The formation of such long-range axonal projections could rely on activity independent and activity-dependent mechanisms. To test if neuronal activity is required for callosal axon projections, and, if it is, to determine which stage(s) of axonal development is activity-dependent, we examined the development of callosal axons in mouse visual cortex under the condition where the activity of callosal projection neurons was reduced [38]. We used a genetic technique of in utero electroporation for labeling callosal axons with EGFP while reducing the activity of callosal projection neurons with a potassium channel Kir2.1, a genetic tool to reduce neuronal activity $[52,53]$. In control animals in which only EGFP was electroporated unilaterally at embryonic day 15 (E15), EGFP was expressed in layer $2 / 3$ cortical excitatory neurons, and EGFP-labeled callosal axons extending from the electroporated hemisphere to the other were observed (Figure 1). In the visual cortex contralateral to the electroporated side, EGFP-labeled callosal axons projected densely to a narrowly restricted region at the border between the primary and secondary visual cortex, in which they terminated mostly in layers 1-3 and 5, and less in layers 4 and 6 (Figure 1(b)). This region-and layer-specific pattern of projection is consistent with the pattern observed in earlier studies using dye tracers $[5,54]$. When Kir2.1 was electroporated with EGFP in layer $2 / 3$ cortical excitatory neurons, their firing rate was reduced [38] as expected from earlier studies $[52,53,55]$. The effect of Kir2.1 expression on callosal axon projections was robust: terminal arborization of EGFP-labeled callosal axons especially in layers 1-3 was dramatically reduced (Figure 1(c)). In contrast, their midline crossing and extension to the target innervation area appeared unaffected. These results suggest that early phases of callosal axon development do not require neuronal activity, but that late phases (e.g., growth of axons and their arbors within the innervation area) are activity-dependent $[38,56]$.

Wang and colleagues took a similar approach to examine the role of neuronal activity in callosal axon projections in the somatosensory cortex [40]. Suppressing excitability of callosal projection neurons by Kir2.1 expression reduces arborization of callosal axons at the border region between the primary and secondary somatosensory cortex, with some aberrant projections radially and tangentially. In addition, they used tetanus toxin light chain (TeNT-LC), a genetic tool to block transmitter release from axon terminals, to show that blocking synaptic transmission also affects callosal axon projections. Interestingly, TeNT-LC expression causes more severe effects on callosal axon projections than Kir2.1 expression: blocking synaptic transmission via TeNT-LC expression produces a more pronounced reduction in the projections to the target cortical layers, and the eventual loss of callosal projections. These results suggest that neuronal and synaptic activities are critically involved in callosal axon projections in the somatosensory cortex. 

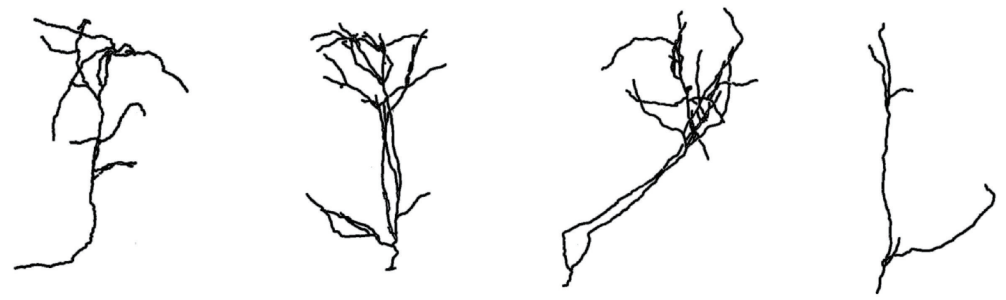

(a) Control
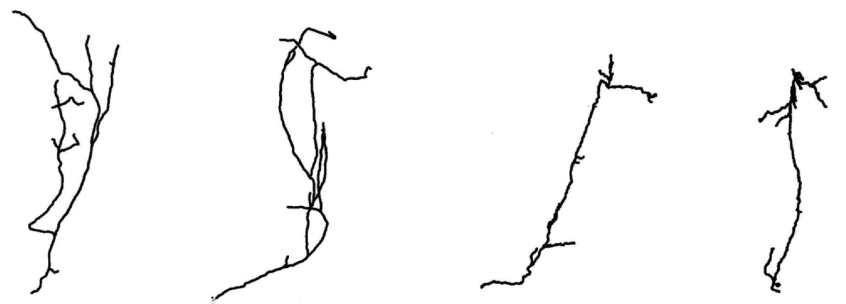

(b) Postsynaptic activity reduction
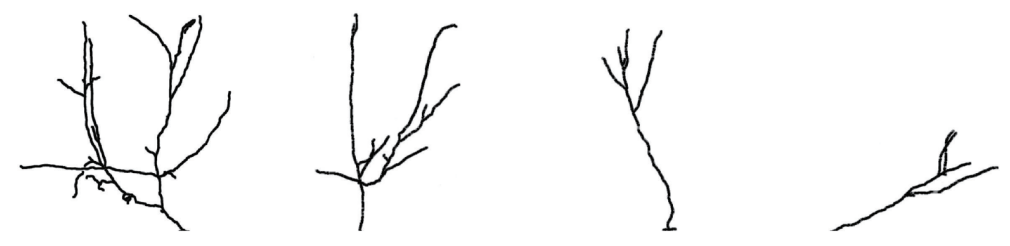

(c) Presynaptic activity reduction

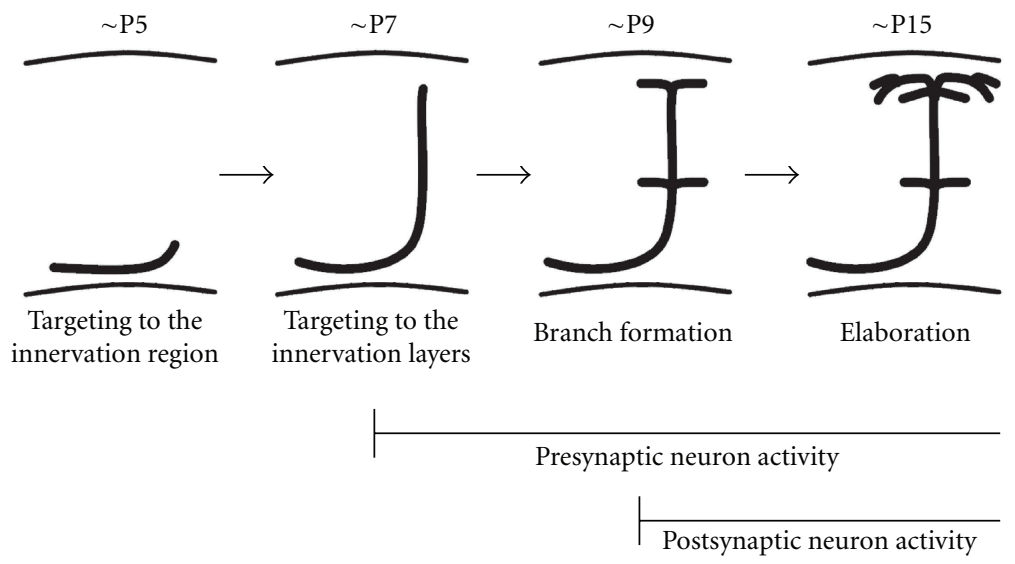

(d)

FIgURE 2: Effects of postsynaptic and presynaptic activity reduction on callosal axon projections. (a) The morphology of single callosal axons in the normal condition at P15. ((b) and (c)) postsynaptic (b) and presynaptic (c) activity reduction impede growth and branching of callosal axons. Scale bar, $200 \mu \mathrm{m}$. (d) An illustration showing the development of callosal axons in the mouse. Callosal axons reach the target innervation area around P5, arrive in the target cortical layers at P7, start to branch at P9, and elaborate their arbors afterwards. The effect of presynaptic activity reduction is apparent before axons reach the target cortical layers, but that of postsynaptic activity reduction is observed after their arrival in the target layers. Adapted from [41].

Many studies have suggested that the formation of connections requires both presynaptic and postsynaptic neuronal activities $[28,29]$. To test if postsynaptic neuronal activity is required for callosal axon projections, we performed more intricate electroporation experiments in which one side of the cortex was electroporated with EGFP for labeling single callosal axons while the other side was electroporated with Kir2.1 for postsynaptic neuron silencing [41]. We found that callosal axons under postsynaptic activity reduction appeared normal until they contacted the putative postsynaptic neurons. However, callosal axons under postsynaptic activity reduction remained less branched after they reached the target cortical layers (Figure 2(b)). This was in contrast with control callosal axons that showed extensive branching (Figure 2(a)). These results suggest that postsynaptic neuronal activity is required for arborization of presynaptic axons after these axons contact the postsynaptic neurons (Figure 2(d)). Axon arbor growth may be enhanced 
by synaptogenesis $[57,58]$; an axon arbor making stable synapses may grow further, while that making less stable synapses may not be able to grow and eventually retract. Formation and maturation of synapses require coordinated presynaptic and postsynaptic activity $[28,29]$. If either (or both) were reduced, synapse formation would be suppressed, which may lead to poor arborization of presynaptic axons. This transsynaptic effect may be mediated by some retrograde signal(s) from postsynaptic neurons to presynaptic axons. Possible candidates would be neurotrophins, which are shown to act as retrograde messengers in mediating activity-dependent strengthening of synaptic connections [59-63].

We also found that the effect of presynaptic neuronal activity reduction was apparent before axons reached the target cortical layers (Figures 2(c) and 2(d)) [41]. This result suggests that the activity of projection neurons themselves plays a role in axonal development before synapse formation. How does activity of callosal projection neurons regulate their own axonal development? Neuronal activity may modulate cytoskeleton rearrangement in the growing axons. Ohnami and colleagues have found that RhoA, a member of Rho family small GTPases, acts as a positive regulator for activity-dependent axon branching in cortical neurons [64]. It is also shown that neuronal activity can modulate the expression or function of some guidance molecules expressed on growing axons, thereby regulating axonal growth, pathfinding, fasciculation, and branching [65-68].

What intracellular signaling mediates activity-dependent axonal development? Kir2.1 overexpression in cortical neurons hyperpolarizes their membrane potential and increases the threshold for evoking action potentials, thereby inhibiting the firing activity $[38,40,52]$. This reduction in firing could attenuate intracellular $\mathrm{Ca}^{2+}$ signaling. It is known that $\mathrm{Ca}^{2+}$ plays a critical role in the regulation of neuronal morphogenesis including dendrite and axon development [69-73]. There are many protein kinases and phosphatases whose activities are regulated by $\mathrm{Ca}^{2+}$. AgetaIshihara and colleagues showed that a member of the $\mathrm{Ca}^{2+}$-dependent kinase family, $\mathrm{Ca}^{2+} /$ calmodulin-dependent protein kinase $\mathrm{I} \alpha(\mathrm{CaMKI} \alpha)$, plays a critical role in callosal axon projections [74]. Using in vitro dissociated culture system, they found that blocking expression or function of CaMKI $\alpha$ specifically impaired axonal, but not dendritic, growth of cortical neurons. They also found that activation of $\mathrm{GABA}_{\mathrm{A}}$ receptors promoted axonal growth in a CaMKI $\alpha$ dependent manner. They further showed that in vivo RNAi knockdown of CaMKI $\alpha$ in callosal projection neurons by in utero electroporation disturbed their axonal projections. It is known that the action of GABA is excitatory in the neonatal period (until two weeks of age) [75]. Although it was not shown whether GABA exerted its action on the cell body and dendrites, or directly on the growing axons, their results suggest that $\mathrm{CaMKI} \alpha$ is critically involved in activitydependent callosal axon projections and that this activity is at least in part mediated by excitatory action of GABA.

Many issues remain to be addressed. For example, the work of Ageta-Ishihara and colleagues suggests that
CaMKI $\alpha$ is an important player which may work downstream of neuronal activity, but other possible candidates $\left(\mathrm{Ca}^{2+}\right.$-dependent and independent intracellular signaling molecules) remain unexplored. In addition, these intracellular signaling molecules would influence the regulation of cytoskeletal proteins, thereby regulating growth and branching of axons, but the precise molecular mechanism is unknown. It is important to note that some of intracellular signaling molecules might work both activity dependently and independently: for example, they may be involved in midline crossing of callosal axons under the control of some guidance molecules and subsequently play a role in axon arbor growth and branching under the control of neuronal activity. If this is the case, intricate experiments such as those using temporally controlled RNAi knockdown of target molecule would be necessary.

Another important issue to be addressed would be the possible relationship between the process of thalamocortical projections and that of the formation of callosal connections. In the visual cortex during the neonatal period, the activity of cortical neurons is modulated by thalamocortical inputs, which transmit activity from the periphery (spontaneously generated massive neuronal activity in the retina, called retinal waves) $[50,76]$. Thalamocortical connectivity develops until P8 in the mouse [77], several days before callosal connectivity forms [38]. Is thalamocortical innervation a prerequisite for callosal connections to establish? Does the activity supplied by thalamocortical inputs play a role in callosal connection formation? These are important not only from a developmental point of view but also from a functional view. Thalamocortical projections are arranged in the cortex in a retinotopic manner, and each visual callosal axon projects to a retinotopically matched region within the visual cortex [78-81]. Olavarria et al. have shown that eye removal during the neonatal period alters retinotopically matched projection pattern of callosal axons $[54,82]$, suggesting a possibility that retinotopic information conveyed through the retino-thalamo-cortical pathway influences callosal connection formation. It would be interesting to examine whether eliminating thalamocortical projections (or suppressing activity of thalamocortical axons) also affects retinotopically organized callosal projection pattern. In addition, whether callosal axons under activity reduction (such as those shown in Figures 2(b) and 2(c)) show retinotopically correct projection pattern or not would be an important issue to be addressed in future.

\section{Patterns of Neuronal Activity Observed in Rat/Mouse Cerebral Cortex during the Neonatal Period}

Recent studies have revealed that several distinct patterns of neuronal activity take place in the rat/mouse cortex during the periods when callosal axon projections develop [4250, 83-85]. Some of them are asynchronous (i.e., neurons fire action potentials individually), and others are network events in which activities of many neurons are synchronized locally or globally (called "cortical waves"). It is important to note 
that neurons in the sensory cortex can fire action potentials without sensory inputs. In development, cortical neurons differentiate to express a combination of ion channels, by which they start to fire action potentials spontaneously. They also start to receive synaptic inputs as cortical network matures, which drive, boost and modulate firing activity of the developing cortical neurons. This neuronal activity, "spontaneously" generated in the developing neurons and cortical network, has been thought to contribute to the formation of connections in the cortex during the developmental period before sensory inputs come in $[28,32,33,45,86]$.

Garaschuk and colleagues used $\mathrm{Ca}^{2+}$ imaging technique to monitor neuronal activity in the developing cortical circuits in a slice preparation [42], and later in the intact brain $[43,49]$. They found that spontaneous oscillatory $\mathrm{Ca}^{2+}$ waves traveled across cortical slices taken from P1$\mathrm{P} 4$ rats and named them cortical early network oscillations (cENOs). cENOs were typically observed once per 1-12 minutes, and many neurons (typically over $80 \%$ of the neurons in the recorded area) participated in the wave. cENOs were completely blocked by AMPA-and NMDA-type glutamate receptor antagonists but not by GABA receptor antagonists, suggesting that cENOs are driven by glutamatergic transmission. Later, by using a similar approach, Allène and colleagues reported another synapse-driven network pattern in neonatal cortical slices, named giant depolarizing potentials (GDPs) [46]. GDPs are different from cENOs, in that they are driven by GABAergic transmission, occur at a higher frequency, recruit smaller number and more localized population of neurons. In addition, GDPs emerge at later stages in cortical development than cENOs (P5-9 for GDPs versus $\mathrm{P} 1-4$ for $\mathrm{cENOs}$ ). These differences may suggest that cENOs and GDPs are involved in different aspects/phases of cortical circuit formation. $\mathrm{Ca}^{2+}$ waves have been observed in vivo rat/mouse cerebral cortex [43, 48-50], but these studies did not determine whether they corresponded to cENOs or GDPs.

Correlated $\mathrm{Ca}^{2+}$ activity mentioned above mostly reflects neuronal firings [46]. Extracellular recordings have detected similar network activities in neonatal rat/mouse cerebral cortex [44, 47, 76, 87, 88]. Yang and colleagues reported three distinct patterns of synchronized oscillatory activity in neonatal rat cortex: spindle-bursts, gamma oscillations, and long oscillations [47]. Spindle-bursts are neuronal burst firings of $1-2 \mathrm{~s}$ in duration, $\sim 10 \mathrm{~Hz}$ in frequency, and observed approximately every $10 \mathrm{~s}$. Gamma oscillations are neuronal activities at a frequency of $30-40 \mathrm{~Hz}$, duration of 150-300 ms, and occur every 10-30 s. Spindle-bursts and gamma oscillations do not propagate but synchronize a local cortical network. In contrast, long oscillations propagate over large cortical regions. They occur every $20 \mathrm{~m}$, last $>40 \mathrm{~s}$, and synchronize in the $10-20 \mathrm{~Hz}$ frequency range over 600 $800 \mu \mathrm{m}$. The precise relationship between the two types of $\mathrm{Ca}^{2+}$ waves (cENOs and GDPs) and the three types of electrical activities (spindle-bursts, gamma oscillations, and long oscillations) is to be clarified.

All three types of electrical activity can be elicited by activation of the periphery. For example, in the somatosensory cortex, tactile, or electrical stimulation of whiskers can induce these network activities [47]. It has also been shown that spontaneously generated correlated activity in the retina (retinal waves) is transmitted to induce spindle-bursts in the visual cortex [76]. However, blocking the peripheral inputs can only reduce, but not eliminate, these network activities, suggesting that the peripheral inputs are not the only mechanism to trigger these activities [50,76]. Spindle-bursts are modulated by cholinergic inputs [89], and microcircuits between cortical neurons and subplate neurons (a transient population of neurons that resides in the neonatal cortical white matter) play a critical role in the generation of spindlebursts [88, 90-92].

Interestingly, spindle-bursts and gamma oscillations are sometimes synchronized between hemispheres [47]. In this experiment, multielectrodes were inserted into both hemispheres simultaneously, and network activity recorded in each hemisphere was compared. The amount of interhemispheric synchronization increases progressively from $\mathrm{P} 0$ to P7, parallel to the development of callosal connections. It is not clear whether this synchronization occurs via callosal connections nor whether these activities can travel between hemispheres though callosal axons; however, surgical transection of the corpus callosum in neonatal rats modulates the expression of spindle-bursts [87], suggesting an existence of interhemispheric communication at this early stage. The synchronized neuronal activities between hemispheres may play a role in the formation and maturation of callosal connections.

The activity of individual cortical neurons and cortical network can be modulated by environmental factors. For example, the emergence of cENOs and GDPs is influenced by experimental conditions such as anoxia and aglycemia [46]. Some cortical network activity during neonatal periods is shown to be influenced by the hormone oxytocin, which is released by the mother during delivery $[46,93]$. Alterations in the activity of individual neurons and network caused by these environmental factors may impede activity-dependent circuit formation in the cortex, including callosal axon projections.

The activity of cortical neurons and network can also be modulated by genetic factors. For example, genetic mutations in ion channels may affect excitability of neurons, causing some diseases such as epilepsy. KCNQ2 is a type of $\mathrm{K}^{+}$channels crucial for the regulation of excitability in cortical neurons, and its genetic mutations are responsible for neonatal epilepsy (benign familial neonatal convulsions: BFNC) [95-99]. All disease-causing mutations in KCNQ2 identified so far result in loss-of-function of channel activity [100]. Transgenic expression of a dominant-negative KCNQ2 mutant channel in developing mouse cerebral cortex is shown to induce spontaneous seizures [94]. Another study shows that a mouse model of human KCNQ2 mutation for BFNC exhibits early onset spontaneous seizures, reminiscent of the phenotype in human patients [101]. In both studies, reduced KCNQ2 channel activity resulted in abnormal cortical activity as recorded by electroencephalogram (EEG) or electrocorticogram (ECoG). Dysfunction of KCNQ2 during the first postnatal week induces morphological changes in the hippocampus [94], implying that repeated seizures 


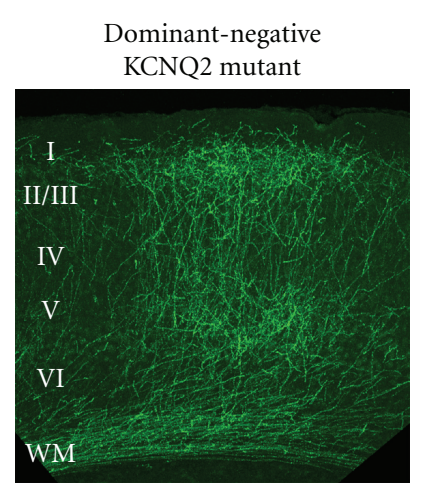

(a)

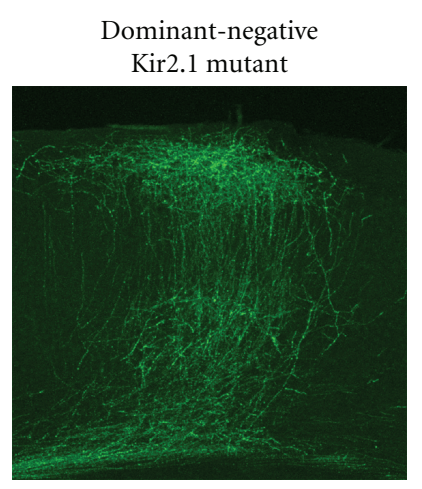

(b)

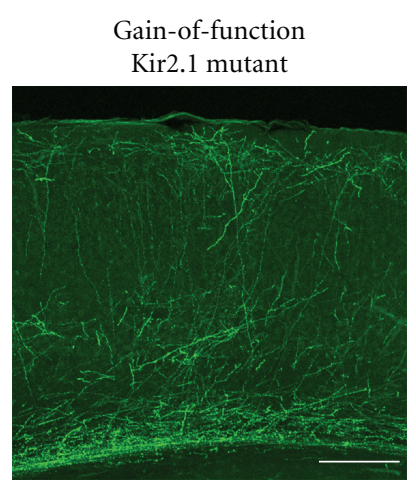

(c)

FIGURE 3: Effects of expression of several ion channels on callosal axon projections. (a) Expression of a dominant-negative KCNQ2 $\mathrm{K}^{+}$ channel [94] does not influence callosal axon development. (b) A disease-causing, dominant-negative Kir2.1 mutant does not impair callosal axon projections. (c) Expression of a gain-of-function Kir2.1 mutant in callosal projection neurons impedes their axonal projections. Scale bar, $200 \mu \mathrm{m}$. Adapted from [38].

during the neonatal period have adverse effects on cortical circuit formation [102, 103].

\section{Do Mutations in Ion Channels Affect Activity-Dependent Callosal Connection Formation?}

To test the idea that activity-dependent callosal axon projections may be affected by mutations in ion channels, we examined the effect of expression of a dominant-negative KCNQ2 mutant channel on callosal axon projections. As shown in Figure 3(a), we observed no apparent defects in overall projection pattern of callosal axons. We also examined the effect of expression of several disease-causing mutant Kir2.1 channels on callosal axon projections [38]. Kir2.1 is expressed in cardiac myocytes as well as cortical neurons, and its genetic mutations are responsible for Andersen syndrome, a disease associated with periodic skeletal muscle paralysis and cardiac arrhythmia $[104,105]$. Most of these mutations result in loss-of-function with dominant-negative suppression of channel activity $[105,106]$. Because reduced Kir2.1 channel activity causes severe manifestations in skeletal and cardiac muscle, we wondered if it might also affect circuit formation in the cerebral cortex. No apparent defects were observed in the development and axonal projection pattern of callosal neurons expressing disease-causing, dominantnegative Kir2.1 mutants [38] (Figure 3(b)). However, we found that a gain-of-function mutation in Kir2.1 (V93I), associated with familial atrial fibrillation (a cardiac disease characterized by rapid and irregular activation of the atrium) [107] caused severe defects in callosal axon projections [38] (Figure 3(c)). It has not been reported that patients with this Kir2.1 mutation have brain phenotypes [107]. However, there are some cases where a single mutation in an ion channel expressed in both heart and brain (e.g., $\mathrm{KCNH} 2$ and KCNQ1) can cause abnormalities in both tissues (cardiac and neural channelopathy) [108-110]. Kir2.1 is expressed in both cardiac myocytes and cortical neurons, and enhanced Kir2.1 activity can have deleterious effects on callosal connection formation. It is therefore possible that anatomical and functional assessment may reveal some abnormality in the structure and/or function of the corpus callosum in patients with the Kir2.1 gain-of-function mutation.

\section{Concluding Remarks}

Callosal connections mediate interhemispheric communication. They serve to integrate and coordinate information between hemispheres, thus involved in higher cognitive functions. Malformations such as partial or complete agenesis of the corpus callosum are associated with many human congenital disorders $[18,111]$, and significant reductions in its size are frequently reported in patients with certain psychiatric and developmental disorders [112-117]. It is important to identify factors affecting function, structure, and development of the corpus callosum.

During development of callosal connections, both activity independent and dependent mechanisms are involved. Many genetic factors responsible for the activity independent processes have been reported [18], but "activity-dependent factors" have not been identified.

Recent advancements in electrophysiological and $\mathrm{Ca}^{2+}$ imaging techniques have enabled us to monitor neuronal activity in neonatal cerebral cortical circuits. These new techniques will be useful to examine how cortical activities are modulated by genetic and environmental factors. Hypoor hyperactivity in neonatal cortical circuits caused by these factors may induce abnormality in the cortical architecture including the corpus callosum. In addition, genetic techniques such as in utero electroporation will allow us to identify molecular signals critical for activity-dependent callosal axon projections. Future work would link the factors that disturb activity-dependent callosal connection formation, with those that influence the patterns of neuronal activity in the developing cortex.

\section{Acknowledgments}

This work was supported by Research Grants from the Ministry of Education, Culture, Sports, Science, and Technology 
(MEXT) of Japan (21700350 and 23500388 to Yoshiaki Tagawa), Grant-in-Aid for Scientific Research on Innovative Areas "Neural Diversity and Neocortical Organization" from MEXT (23123508 to Yoshiaki Tagawa).

\section{References}

[1] D. Hubel and T. Wiesel, "Cortical and callosal connections concerned with the vertical meridian of visual fields in the cat," Journal of Neurophysiology, vol. 30, no. 6, pp. 1561-1573, 1967.

[2] C. J. Shatz, "Anatomy of interhemispheric connections in the visual system of Boston Siamese and ordinary cats," Journal of Comparative Neurology, vol. 173, no. 3, pp. 497-518, 1977.

[3] D. van Essen, W. Newsome, and J. Bixby, "The pattern of interhemispheric connections and its relationship to extrastriate visual areas in the macaque monkey," Journal of Neuroscience, vol. 2, no. 3, pp. 265-283, 1982.

[4] C. Blakemore, Y. Diao, M. Pu, Y. Wang, and Y. Xiao, "Possible functions of the interhemispheric connexions between visual cortical areas in the cat," Journal of Physiology, vol. 337, pp. 331-349, 1983.

[5] J. Olavarria and V. M. Montero, "Relation of callosal and striate-extrastriate cortical connections in the rat: morphological definition of extrastriate visual areas," Experimental Brain Research, vol. 54, no. 2, pp. 240-252, 1984.

[6] G. M. Innocenti, S. Clarke, and R. Kraftsik, "Intercharge of callosal and association projections in the developing visual cortex," Journal of Neuroscience, vol. 6, no. 5, pp. 1384-1409, 1986.

[7] G. M. Innocenti and D. J. Price, "Exuberance in the development of cortical networks," Nature Reviews Neuroscience, vol. 6, no. 12, pp. 955-965, 2005.

[8] M. Pietrasanta, L. Restani, and M. Caleo, "The corpus callosum and the visual cortex: plasticity is a game for two," Neural Plasticity, vol. 2012, Article ID 838672, 2012.

[9] M. Nieto, E. S. Monuki, H. Tang et al., "Expression of Cux-1 and Cux-2 in the subventricular zone and upper layers II-IV of the cerebral cortex," Journal of Comparative Neurology, vol. 479, no. 2, pp. 168-180, 2004.

[10] E. A. Alcamo, L. Chirivella, M. Dautzenberg et al., "Satb2 regulates callosal projection neuron identity in the developing cerebral cortex," Neuron, vol. 57, no. 3, pp. 364-377, 2008.

[11] O. Britanova, C. de Juan Romero, A. Cheung et al., "Satb2 Is a postmitotic determinant for upper-layer neuron specification in the neocortex," Neuron, vol. 57, no. 3, pp. 378-392, 2008.

[12] R. M. Fame, J. L. Macdonald, and J. D. Macklis, "Development, specification, and diversity of callosal projection neurons," Trends in Neurosciences, vol. 34, no. 1, pp. 41-50, 2011.

[13] T. Serafini, S. A. Colamarino, E. D. Leonardo et al., "Netrin-1 is required for commissural axon guidance in the developing vertebrate nervous system," Cell, vol. 87, no. 6, pp. 10011014, 1996.

[14] A. Fazeli, S. L. Dickinson, M. L. Hermiston et al., "Phenotype of mice lacking functional deleted in colorectal cancer (Dcc) gene," Nature, vol. 386, no. 6627, pp. 796-804, 1997.

[15] A. Bagri, O. Marín, A. S. Plump et al., "Slit proteins prevent midline crossing and determine the dorsoventral position of major axonal pathways in the mammalian forebrain," Neuron, vol. 33, no. 2, pp. 233-248, 2002.
[16] Z. Hu, X. Yue, G. Shi et al., "corpus callosum deficiency in transgenic mice expressing a truncated ephrin-A receptor," Journal of Neuroscience, vol. 23, no. 34, pp. 10963-10970, 2003.

[17] T. Shu, V. Sundaresan, M. M. Mccarthy, and L. J. Richards, "Slit2 guides both precrossing and postcrossing callosal axons at the midline in vivo," Journal of Neuroscience, vol. 23, no. 22, pp. 8176-8184, 2003.

[18] L. J. Richards, C. Plachez, and T. Ren, "Mechanisms regulating the development of the corpus callosum and its agenesis in mouse and human," Clinical Genetics, vol. 66, no. 4, pp. 276-289, 2004.

[19] W. Andrews, A. Liapi, C. Plachez et al., "Robo1 regulates the development of major axon tracts and interneuron migration in the forebrain," Development, vol. 133, no. 11, pp. 22432252, 2006.

[20] T. R. Keeble, M. M. Halford, C. Seaman et al., "The Wnt receptor Ryk is required for Wnt5a-mediated axon guidance on the contralateral side of the corpus callosum," Journal of Neuroscience, vol. 26, no. 21, pp. 5840-5848, 2006.

[21] S. W. Mendes, M. Henkemeyer, and D. J. Liebl, "Multiple Eph receptors and B-class ephrins regulate midline crossing of corpus callosum fibers in the developing mouse forebrain," Journal of Neuroscience, vol. 26, no. 3, pp. 882-892, 2006.

[22] C. Lindwall, T. Fothergill, and L. J. Richards, "Commissure formation in the mammalian forebrain," Current Opinion in Neurobiology, vol. 17, no. 1, pp. 3-14, 2007.

[23] T. Ren, J. Zhang, C. Plachez, S. Mori, and L. J. Richards, "Diffusion tensor magnetic resonance imaging and tracttracing analysis of probst bundle structure in netrin1- and DCC-deficient mice," Journal of Neuroscience, vol. 27, no. 39, pp. 10345-10349, 2007.

[24] G. López-Bendito, N. Flames, L. Ma et al., "Robo1 and Robo2 cooperate to control the guidance of major axonal tracts in the mammalian forebrain," Journal of Neuroscience, vol. 27, no. 13, pp. 3395-3407, 2007.

[25] L. Li, B. I. Hutchins, and K. Kalil, "Wnt5a induces simultaneous cortical axon outgrowth and repulsive axon guidance through distinct signaling mechanisms," Journal of Neuroscience, vol. 29, no. 18, pp. 5873-5883, 2009.

[26] M. Piper, C. Plachez, O. Zalucki et al., "Neuropilin 1-Sema signaling regulates crossing of cingulate pioneering axons during development of the corpus callosum," Cerebral cortex, vol. 19, pp. i11-i21, 2009.

[27] M. Nishikimi, K. Oishi, H. Tabata, K. Torii, and K. Nakajima, "Segregation and pathfinding of callosal axons through EphA3 signaling," Journal of Neuroscience, vol. 31, no. 45, pp. 16251-16260, 2011.

[28] L. C. Katz and C. J. Shatz, "Synaptic activity and the construction of cortical circuits," Science, vol. 274, no. 5290, pp. 1133-1138, 1996.

[29] H. Cline, "Sperry and hebb: oil and vinegar?" Trends in Neurosciences, vol. 26, no. 12, pp. 655-661, 2003.

[30] M. Sur and J. L. Rubenstein, "Patterning and plasticity of the cerebral cortex," Science, vol. 310, no. 5749, pp. 805-810, 2005.

[31] A. D. Huberman, M. B. Feller, and B. Chapman, "Mechanisms underlying development of visual maps and receptive fields," Annual Review of Neuroscience, vol. 31, pp. 479-509, 2008.

[32] A. Bleckert and R. O. Wong, "Identifying roles for neurotransmission in circuit assembly: insights gained from multiple model systems and experimental approaches," Bioessays, vol. 33, no. 1, pp. 61-72, 2011. 
[33] N. Yamamoto and G. López-Bendito, "Shaping brain connections through spontaneous neural activity," European Journal of Neuroscience, vol. 35, no. 10, pp. 1595-1604, 2012.

[34] G. M. Innocenti and D. O. Frost, "Effects of visual experience on the maturation of the efferent system to the corpus callosum," Nature, vol. 280, no. 5719, pp. 231-234, 1979.

[35] C. Cusick and R. Lund, "Modification of visual callosal projections in rats," Journal of Comparative Neurology, vol. 212, no. 4, pp. 385-398, 1982.

[36] J. Olavarria, R. Malach, and R. C. van Sluyters, "Development of visual callosal connections in neonatally enucleated rats," Journal of Comparative Neurology, vol. 260, no. 3, pp. 321348, 1987.

[37] P. D. Zufferey, F. Jin, H. Nakamura, L. Tettoni, and G. M. Innocenti, "The role of pattern vision in the development of cortico-cortical connections," European Journal of Neuroscience, vol. 11, no. 8, pp. 2669-2688, 1999.

[38] H. Mizuno, T. Hirano, and Y. Tagawa, "Evidence for activitydependent cortical wiring: formation of interhemispheric connections in neonatal mouse visual cortex requires projection neuron activity," Journal of Neuroscience, vol. 27, no. 25, pp. 6760-6770, 2007.

[39] D. L. Chao and G. J. Wang, "Firing to wire: a role for activity in establishing layer specificity in the cortex," Journal of Neuroscience, vol. 27, no. 41, pp. 10922-10923, 2007.

[40] C. L. Wang, L. Zhang, Y. Zhou et al., "Activity-dependent development of callosal projections in the somatosensory cortex," Journal of Neuroscience, vol. 27, no. 42, pp. 1133411342, 2007.

[41] H. Mizuno, T. Hirano, and Y. Tagawa, "Pre-synaptic and post-synaptic neuronal activity supports the axon development of callosal projection neurons during different postnatal periods in the mouse cerebral cortex," European Journal of Neuroscience, vol. 31, no. 3, pp. 410-424, 2010.

[42] O. Garaschuk, J. Linn, J. Eilers, and A. Konnerth, "Large-scale oscillatory calcium waves in the immature cortex," Nature Neuroscience, vol. 3, no. 5, pp. 452-459, 2000.

[43] H. Adelsberger, O. Garaschuk, and A. Konnerth, "Cortical calcium waves in resting newborn mice," Nature Neuroscience, vol. 8, no. 8, pp. 988-990, 2005.

[44] R. Khazipov, A. Sirota, X. Leinekugel, G. L. Holmes, Y. BenAri, and G. Buzsáki, "Early motor activity drives spindle bursts in the developing somatosensory cortex," Nature, vol. 432, no. 7018, pp. 758-761, 2004.

[45] R. Khazipov and H. J. Luhmann, "Early patterns of electrical activity in the developing cerebral cortex of humans and rodents," Trends in Neurosciences, vol. 29, no. 7, pp. 414-418, 2006.

[46] C. Allène, A. Cattani, J. B. Ackman et al., "Sequential generation of two distinct synapse-driven network patterns in developing neocortex," Journal of Neuroscience, vol. 28, no. 48, pp. 12851-12863, 2008.

[47] J. W. Yang, I. L. Hanganu-Opatz, J. J. Sun, and H. J. Luhmann, "Three patterns of oscillatory activity differentially synchronize developing neocortical networks in vivo," Journal of Neuroscience, vol. 29, no. 28, pp. 9011-9025, 2009.

[48] P. Golshani, J. T. Gonçalves, S. Khoshkhoo, R. Mostany, S. Smirnakis, and C. Portera-Cailliau, "Internally mediated developmental desynchronization of neocortical network activity," Journal of Neuroscience, vol. 29, no. 35, pp. 1089010899, 2009.

[49] N. L. Rochefort, O. Garaschuk, R. I. Milos et al., "Sparsification of neuronal activity in the visual cortex at eye-opening,"
Proceedings of the National Academy of Sciences of the United States of America, vol. 106, no. 35, pp. 15049-15054, 2009.

[50] F. Siegel, J. A. Heimel, J. Peters, and C. Lohmann, "Peripheral and central inputs shape network dynamics in the developing visual cortex in vivo," Current Biology, vol. 22, no. 3, pp. 253$258,2012$.

[51] S. Jacobson and J. Q. Trojanowski, "The cells of origin of the corpus callosum in rat, cat and rhesus monkey," Brain Research, vol. 74, no. 1, pp. 149-155, 1974.

[52] D. C. Johns, R. Marx, R. E. Mains, B. O'Rourke, and E. Marbán, "Inducible genetic suppression of neuronal excitability," Journal of Neuroscience, vol. 19, no. 5, pp. 16911697, 1999.

[53] J. Burrone, M. O’Byrne, and V. N. Murthy, "Multiple forms of synaptic plasticity triggered by selective suppression of activity in individual neurons," Nature, vol. 420, no. 6914, pp. 414-418, 2002.

[54] J. F. Olavarria and P. Safaeian, "Development of callosal topography in visual cortex of normal and enucleated rats," Journal of Comparative Neurology, vol. 496, no. 4, pp. 495512, 2006.

[55] C. R. Yu, J. Power, G. Barnea et al., "Spontaneous neural activity is required for the establishment and maintenance of the olfactory sensory map," Neuron, vol. 42, no. 4, pp. 553566, 2004.

[56] Y. Tagawa, H. Mizuno, and T. Hirano, "Activity-dependent development of interhemispheric connections in the visual cortex," Reviews in the Neurosciences, vol. 19, no. 1, pp. 1928, 2008.

[57] M. P. Meyer and S. J. Smith, "Evidence from in vivo imaging that synaptogenesis guides the growth and branching of axonal arbors by two distinct mechanisms," Journal of Neuroscience, vol. 26, no. 13, pp. 3604-3614, 2006.

[58] E. S. Ruthazer, J. Li, and H. T. Cline, "Stabilization of axon branch dynamics by synaptic maturation," Journal of Neuroscience, vol. 26, no. 13, pp. 3594-3603, 2006.

[59] L. Maffei, N. Berardi, L. Domenici, V. Parisi, and T. Pizzorusso, "Nerve growth factor (NGF) prevents the shift in ocular dominance distribution of visual cortical neurons in monocularly deprived rats," Journal of Neuroscience, vol. 12, no. 12, pp. 4651-4662, 1992.

[60] R. J. Cabelli, A. Hohn, and C. J. Shatz, "Inhibition of ocular dominance column formation by infusion of NT-4/5 or BDNF," Science, vol. 267, no. 5204, pp. 1662-1667, 1995.

[61] S. Cohen-Cory and S. E. Fraser, "Effects of brain-derived neurotrophic factor on optic axon branching and remodelling in vivo," Nature, vol. 378, no. 6553, pp. 192-196, 1995.

[62] H. Thoenen, "Neurotrophins and neuronal plasticity," Science, vol. 270, no. 5236, pp. 593-598, 1995.

[63] X. H. Wang and M. M. Poo, "Potentiation of developing synapses by postsynaptic release of neurotrophin-4," Neuron, vol. 19, no. 4, pp. 825-835, 1997.

[64] S. Ohnami, M. Endo, S. Hirai et al., "Role of RhoA in activitydependent cortical axon branching," Journal of Neuroscience, vol. 28, no. 37, pp. 9117-9121, 2008.

[65] M. G. Hanson and L. T. Landmesser, "Normal patterns of spontaneous activity are required for correct motor axon guidance and the expression of specific guidance molecules," Neuron, vol. 43, no. 5, pp. 687-701, 2004.

[66] S. Serizawa, K. Miyamichi, H. Takeuchi, Y. Yamagishi, M. Suzuki, and H. Sakano, "A neuronal identity code for the odorant receptor-specific and activity-dependent axon sorting," Cell, vol. 127, no. 5, pp. 1057-1069, 2006. 
[67] X. Nicol, S. Voyatzis, A. Muzerelle et al., "cAMP oscillations and retinal activity are permissive for ephrin signaling during the establishment of the retinotopic map," Nature Neuroscience, vol. 10, no. 3, pp. 340-347, 2007.

[68] E. Mire, C. Mezzera, E. Leyva-Díz et al., "Spontaneous activity regulates Robol transcription to mediate a switch in thalamocortical axon growth," Nature Neuroscience, vol. 15, no. 8, pp. 1134-1143, 2012.

[69] R. O. L. Wong and A. Ghosh, "Activity-dependent regulation of dendritic growth and patterning," Nature Reviews Neuroscience, vol. 3, no. 10, pp. 803-812, 2002.

[70] C. Lohmann and R. O. L. Wong, "Regulation of dendritic growth and plasticity by local and global calcium dynamics," Cell Calcium, vol. 37, no. 5, pp. 403-409, 2005.

[71] J. Q. Zheng and M. M. Poo, "Calcium signaling in neuronal motility," Annual Review of Cell and Developmental Biology, vol. 23, pp. 375-404, 2007.

[72] S. Takemoto-Kimura, K. Suzuki, S. Kamijo et al., "Differential roles for CaM kinases in mediating excitationmorphogenesis coupling during formation and maturation of neuronal circuits," The European Journal of Neuroscience, vol. 32, no. 2, pp. 224-230, 2010.

[73] S. S. Rosenberg and N. C. Spitzer, "Calcium signaling in neuronal development," Cold Spring Harbor Perspectives in Biology, vol. 3, no. 10, Article ID a004259, pp. 1-13, 2011.

[74] N. Ageta-Ishihara, S. Takemoto-Kimura, M. Nonaka et al., "Control of cortical axon elongation by a GABA-driven $\mathrm{Ca}^{2+} /$ calmodulin-dependent protein kinase cascade," Journal of Neuroscience, vol. 29, no. 43, pp. 13720-13729, 2009.

[75] Y. Ben-Ari, "Excitatory actions of GABA during development: the nature of the nurture," Nature Reviews Neuroscience, vol. 3, no. 9, pp. 728-739, 2002.

[76] I. L. Hanganu, Y. Ben-Ari, and R. Khazipov, "Retinal waves trigger spindle bursts in the neonatal rat visual cortex," Journal of Neuroscience, vol. 26, no. 25, pp. 6728-6736, 2006.

[77] G. López-Bendito and Z. Molnár, "Thalamocortical development: how are we going to get there?" Nature Reviews Neuroscience, vol. 4, no. 4, pp. 276-289, 2003.

[78] G. Berlucchi and G. Rizzolatti, "Binocularly driven neurons in visual cortex of split-chiasm cats," Science, vol. 159, no. 3812, pp. 308-310, 1968.

[79] G. Innocenti, "General organization of callosal connections in the cerebral cortex," in Cerebral Cortex, E. G. Jones and A. Peters, Eds., vol. 5, pp. 291-353, Plenum Press, New York, NY, USA, 1986.

[80] J. F. Olavarria, "Non-mirror-symmetric patterns of callosal linkages in areas 17 and 18 in cat visual cortex," Journal of Comparative Neurology, vol. 366, no. 4, pp. 643-655, 1996.

[81] M. P. Stryker and A. Antonini, "Factors shaping the corpus callosum," Journal of Comparative Neurology, vol. 433, no. 4, pp. 437-440, 2001.

[82] J. F. Olavarria and R. Hiroi, "Retinal influences specify cortico-cortical maps by postnatal day six in rats and mice," Journal of Comparative Neurology, vol. 459, no. 2, pp. 156172, 2003.

[83] R. Yuste, A. Peinado, and L. C. Katz, "Neuronal domains in developing neocortex," Science, vol. 257, no. 5070, pp. 665$669,1992$.

[84] C. Allene and R. Cossart, "Early NMDA receptor-driven waves of activity in the developing neocortex: physiological or pathological network oscillations?" Journal of Physiology, vol. 588, no. 1, pp. 83-91, 2010.

[85] J. Conhaim, C. R. Easton, M. I. Becker et al., "Developmental changes in propagation patterns and transmitter dependence of waves of spontaneous activity in the mouse cerebral cortex," Journal of Physiology, vol. 589, no. 10, pp. 2529-2541, 2011.

[86] A. G. Blankenship and M. B. Feller, "Mechanisms underlying spontaneous patterned activity in developing neural circuits," Nature Reviews Neuroscience, vol. 11, no. 1, pp. 18-29, 2010.

[87] A. J. Marcano-Reik and M. S. Blumberg, "The corpus callosum modulates spindle-burst activity within homotopic regions of somatosensory cortex in newborn rats," European Journal of Neuroscience, vol. 28, no. 8, pp. 1457-1466, 2008.

[88] E. A. Tolner, A. Sheikh, A. Y. Yukin, K. Kaila, and P. O. Kanold, "Subplate neurons promote spindle bursts and thalamocortical patterning in the neonatal rat somatosensory cortex," Journal of Neuroscience, vol. 32, no. 2, pp. 692-702, 2012.

[89] I. L. Hanganu, J. F. Staiger, Y. Ben-Ari, and R. Khazipov, "Cholinergic modulation of spindle bursts in the neonatal rat visual cortex in vivo," Journal of Neuroscience, vol. 27, no. 21, pp. 5694-5705, 2007.

[90] E. Dupont, I. L. Hanganu, W. Kilb, S. Hirsch, and H. J. Luhmann, "Rapid developmental switch in the mechanisms driving early cortical columnar networks," Nature, vol. 439, no. 7072, pp. 79-83, 2006.

[91] I. L. Hanganu, A. Okabe, V. Lessmann, and H. J. Luhmann, "Cellular mechanisms of subplate-driven and cholinergic input-dependent network activity in the neonatal rat somatosensory cortex," Cerebral Cortex, vol. 19, no. 1, pp. 89$105,2009$.

[92] P. O. Kanold and H. J. Luhmann, "The subplate and early cortical circuits," Annual Review of Neuroscience, vol. 33, pp. 23-48, 2010.

[93] V. Crépel, D. Aronov, I. Jorquera, A. Represa, Y. Ben-Ari, and R. Cossart, "A parturition-associated nonsynaptic coherent activity pattern in the developing hippocampus," Neuron, vol. 54, no. 1, pp. 105-120, 2007.

[94] H. C. Peters, H. Hu, O. Pongs, J. F. Storm, and D. Isbrandt, "Conditional transgenic suppression of $\mathrm{M}$ channels in mouse brain reveals functions in neuronal excitability, resonance and behavior," Nature Neuroscience, vol. 8, no. 1, pp. 51-60, 2005.

[95] C. Biervert, B. C. Schroeder, C. Kubisch et al., "A potassium channel mutation in neonatal human epilepsy," Science, vol. 279, no. 5349, pp. 403-406, 1998.

[96] C. Charlier, N. A. Singh, S. G. Ryan et al., "A pore mutation in a novel KQT-like potassium channel gene in an idiopathic epilepsy family," Nature Genetics, vol. 18, no. 1, pp. 53-55, 1998.

[97] N. A. Singh, C. Charlier, D. Stauffer et al., "A novel potassium channel gene, KCNQ2, is mutated in an inherited epilepsy of newborns," Nature Genetics, vol. 18, no. 1, pp. 25-29, 1998.

[98] T. J. Jentsch, "Neuronal KCNQ potassium channels: physiology and role in disease," Nature Reviews Neuroscience, vol. 1, no. 1, pp. 21-30, 2000.

[99] N. A. Singh, P. Westenskow, C. Charlier et al., "KCNQ2 and $K C N Q 3$ potassium channel genes in benign familial neonatal convulsions: expansion of the functional and mutation spectrum," Brain, vol. 126, no. 12, pp. 2726-2737, 2003.

[100] S. Maljevic, T. V. Wuttke, and H. Lerche, "Nervous system KV7 disorders: breakdown of a subthreshold brake," Journal of Physiology, vol. 586, no. 7, pp. 1791-1801, 2008.

[101] N. A. Singh, J. F. Otto, E. J. Dahle et al., "Mouse models of human KCNQ2 and KCNQ3 mutations for benign familial neonatal convulsions show seizures and neuronal plasticity 
without synaptic reorganization," Journal of Physiology, vol. 586, no. 14, pp. 3405-3423, 2008.

[102] Y. Ben-Ari and G. L. Holmes, "Effects of seizures on developmental processes in the immature brain," Lancet Neurology, vol. 5, no. 12, pp. 1055-1063, 2006.

[103] Y. Bozzi, S. Casarosa, and M. Caleo, "Epilepsy as a neurodevelopmental disorder," Frontiers in Psychiatry, vol. 3, Article ID 19, 2012.

[104] N. M. Plaster, R. Tawil, M. Tristani-Firouzi et al., "Mutations in Kir2.1 cause the developmental and episodic electrical phenotypes of Andersen's syndrome," Cell, vol. 105, no. 4, pp. 511-519, 2001.

[105] M. Tristani-Firouzi, J. L. Jensen, M. R. Donaldson et al., "Functional and clinical characterization of KCNJ2 mutations associated with LQT7 (Andersen syndrome)," Journal of Clinical Investigation, vol. 110, no. 3, pp. 381-388, 2002.

[106] S. Bendahhou, M. R. Donaldson, N. M. Plaster, M. TristaniFirouzi, Y. H. Fu, and L. J. Ptácek, "Defective potassium channel Kir2.1 trafficking underlies Andersen-Tawil syndrome," Journal of Biological Chemistry, vol. 278, no. 51, pp. 5177951785, 2003.

[107] M. Xia, Q. Jin, S. Bendahhou et al., "A Kir2.1 gainof-function mutation underlies familial atrial fibrillation," Biochemical and Biophysical Research Communications, vol. 332, no. 4, pp. 1012-1019, 2005.

[108] J. N. Johnson, N. Hofman, C. M. Haglund, G. D. Cascino, A. A. M. Wilde, and M. J. Ackerman, "Identification of a possible pathogenic link between congenital long QT syndrome and epilepsy," Neurology, vol. 72, no. 3, pp. 224231, 2009.

[109] A. M. Goldman, E. Glasscock, J. Yoo, T. T. Chen, T. L. Klassen, and J. L. Noebels, "Arrhythmia in heart and brain: KCNQ1 mutations link epilepsy and sudden unexplained death," Science translational medicine, vol. 1, no. 2, p. 2ra6, 2009.

[110] C. Omichi, Y. Momose, and S. Kitahara, "Congenital long QT syndrome presenting with a history of epilepsy: misdiagnosis or relationship between channelopathies of the heart and brain?” Epilepsia, vol. 51, no. 2, pp. 289-292, 2010.

[111] D. Kamnasaran, "Agenesis of the corpus callosum: lessons from humans and mice," Clinical and Investigative Medicine, vol. 28, no. 5, pp. 267-282, 2005.

[112] J. Bodensteiner, G. B. Schaefer, L. Breeding, and L. Cowan, "Hypoplasia of the corpus callosum: a study of 445 consecutive MRI scans," Journal of Child Neurology, vol. 9, no. 1, pp. 47-49, 1994.

[113] B. Egaas, E. Courchesne, and O. Saitoh, "Reduced size of corpus callosum in autism," Archives of Neurology, vol. 52, no. 8, pp. 794-801, 1995.

[114] J. S. Bloom and G. W. Hynd, "The role of the corpus callosum in interhemispheric transfer of information: excitation or inhibition?" Neuropsychology Review, vol. 15, no. 2, pp. 5971, 2005.

[115] C. N. Vidal, R. Nicolson, T. J. DeVito et al., "Mapping corpus callosum deficits in autism: an index of aberrant cortical connectivity," Biological Psychiatry, vol. 60, no. 3, pp. 218225, 2006.

[116] D. Arnone, A. M. McIntosh, P. Chandra, and K. P. Ebmeier, "Meta-analysis of magnetic resonance imaging studies of the corpus callosum in bipolar disorder," Acta Psychiatrica Scandinavica, vol. 118, no. 5, pp. 357-362, 2008.
[117] J. Miyata, M. Yamada, C. Namiki et al., "Reduced white matter integrity as a neural correlate of social cognition deficits in schizophrenia," Schizophrenia Research, vol. 119, no. 1-3, pp. 232-239, 2010. 

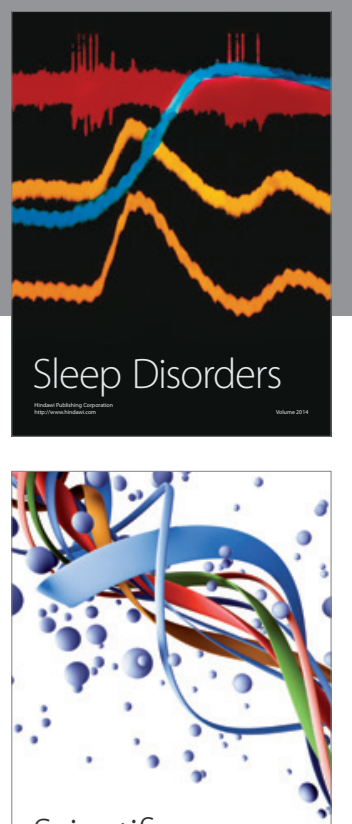

Scientifica
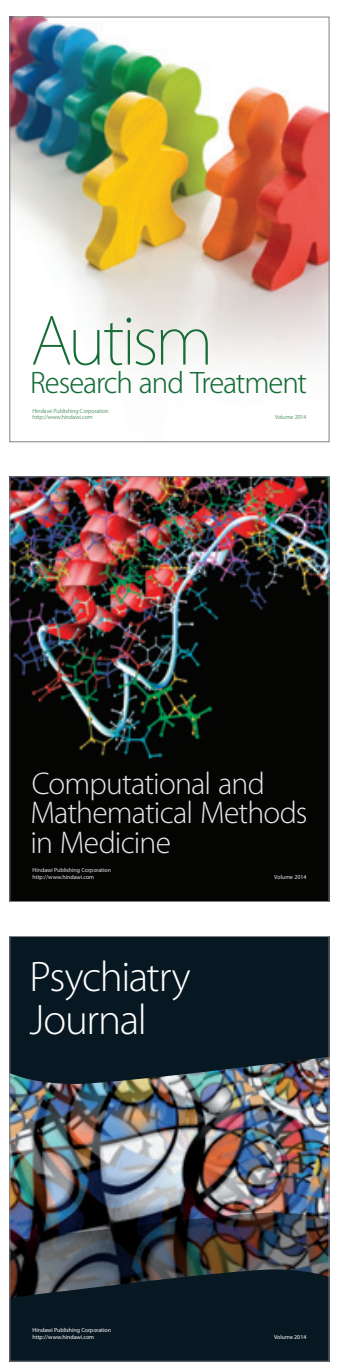
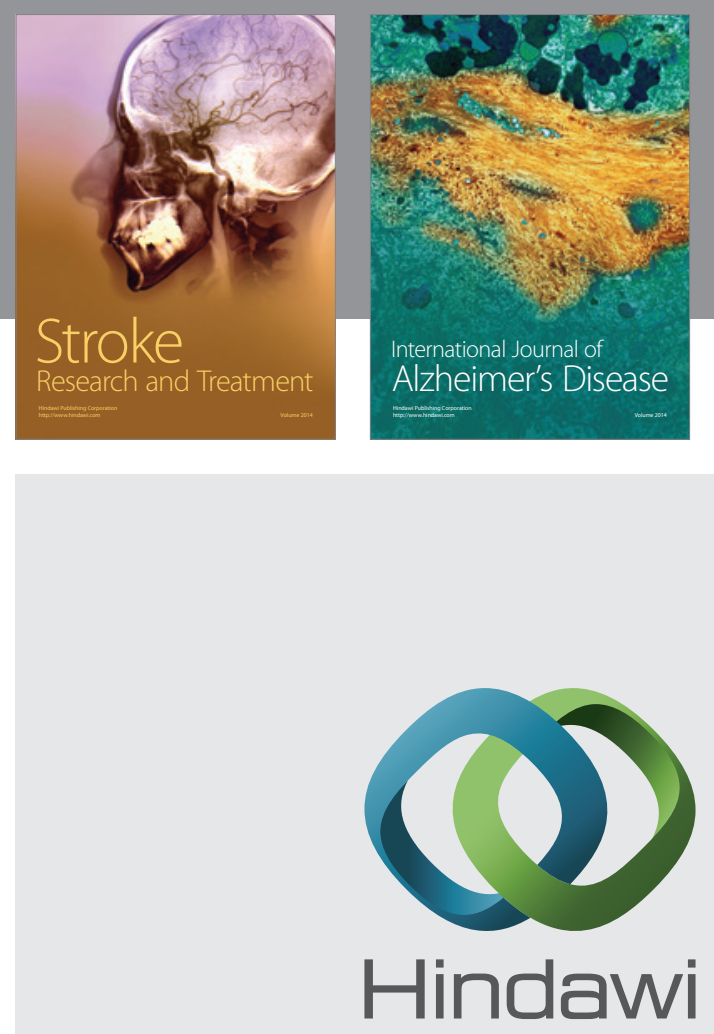

Submit your manuscripts at

http://www.hindawi.com
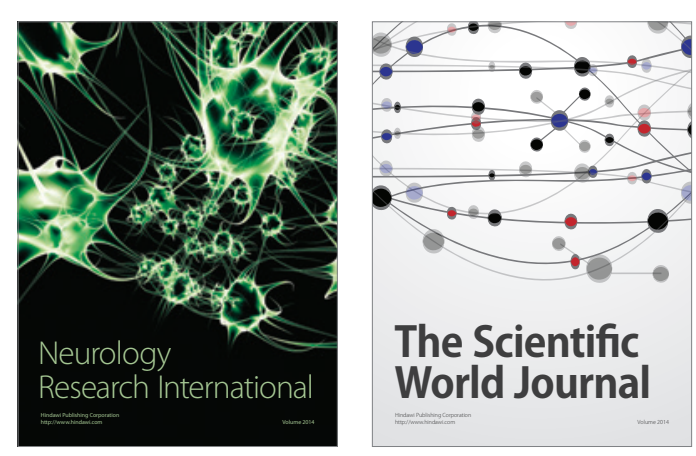

The Scientific World Journal

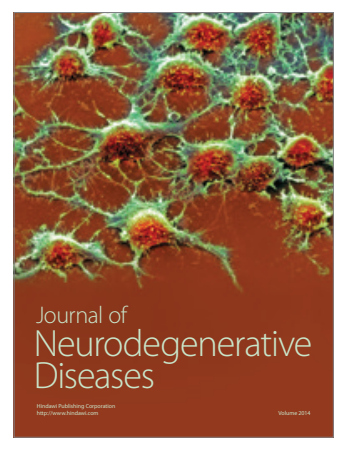

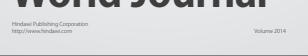

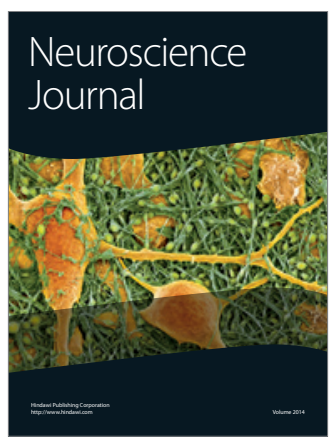

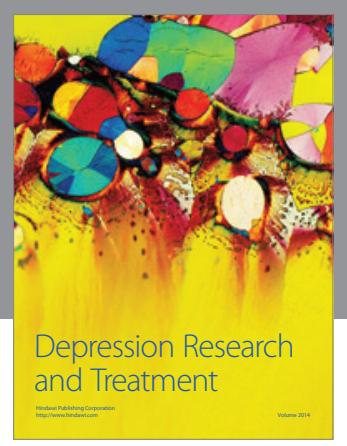
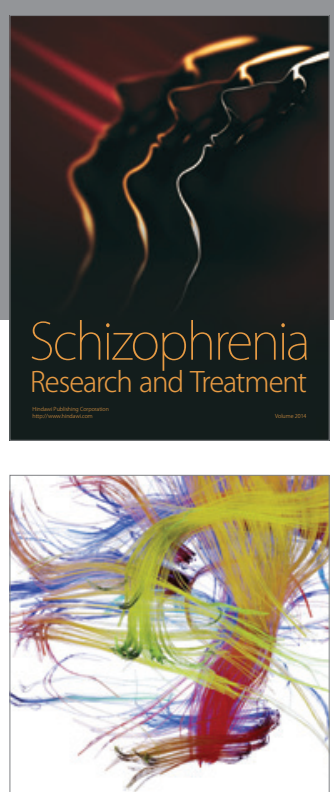

Brain Science

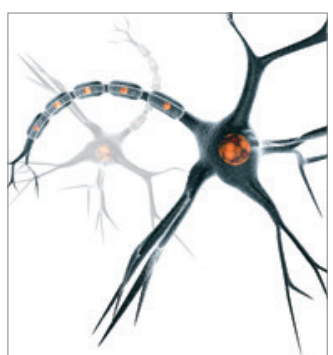

Neural Plasticity
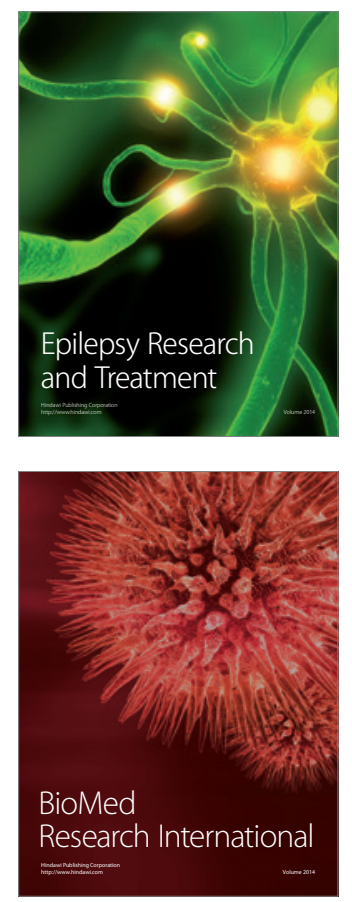

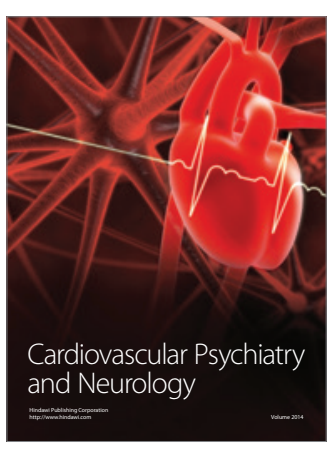

Parkinson's

Disease
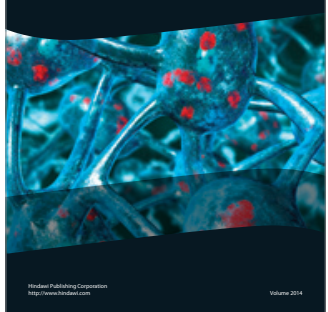